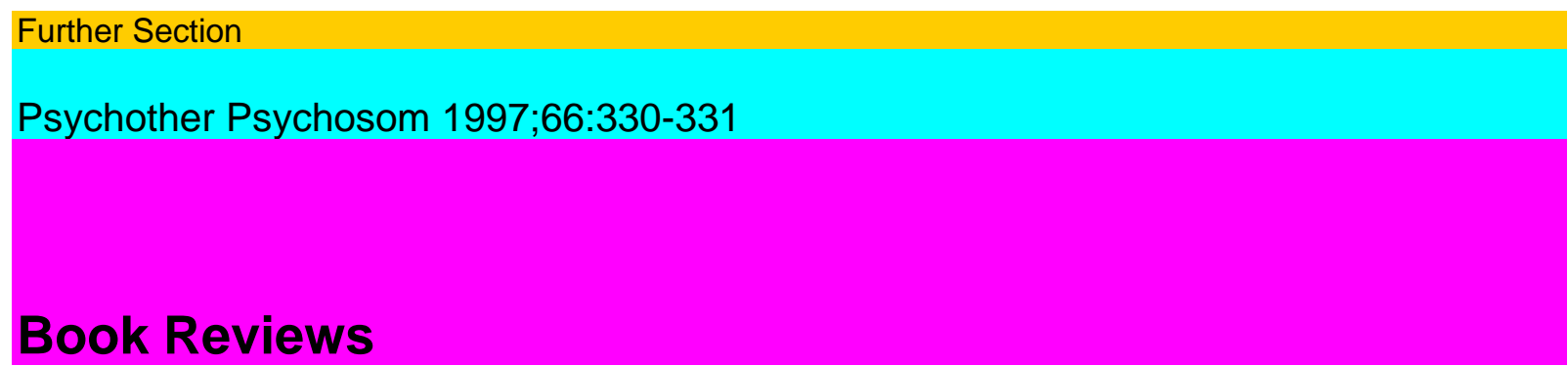

Psychotherapy and Psychosomatics

U. T. Egle, S. 0. Hofmann, P. Joraschky Sexueller Missbrauch, Misshandlung, Vernachlässigung Schattauer, Stuttgart 1997. 476 pp., 18 fig., 22 tab.; DEM 39.-ISBN3-7945-1625-7

B. Dulz, A. Schneider

Borderline-Störungen. Theorie und Therapie;

2. Aufl.

Schattauer, Stuttgart 1996. 186 pp.; DEM 49.-

ISBN3-7945-1728-8

\title{
S. Ahrens
}

Lehrbuch der Psychotherapeutischen Medizin

Schattauer, Stuttgart 1997.704 pp.; 18 fig., 18 tab.; DEM 98.-ISBN3-7945-1627-3

J. Bauer

Die Alzheimer-Krankheit; IMeurobiologie,

Psychosomatik, Diagnostik und Therapie

Schattauer, Stuttgart 1995. 144 pp.; DEM 48.-ISBN3-7945-1634-6

Starting from the systematic German-language program entitled 'Psychosomatics

Psychotherapy’ published by the Schattauer publishing house, Stuttgart, Germany, early 1990

seven book reviews were presented in Psychother Psychosom 1994, vol 62, pp 221-223. The

scientific director of the company, Dr. Wulf Bertram, doctor and psychologist, is the trendsetter

of this new development. Now we should like to review four further Schattauer books which are

also characteristic of current tendencies in the German psychosomatics-psychotherapy field.

'Sexual abuse, bodily maltreatment, emotional neglect' by Dr. Ulrich-Tiber Egle (Senior

Physician, Department of Psychosomatics and Psychotherapy, University of Mainz, Germany)

and coworkers includes qualitatively high information concerning a topic which is very relevant around the world today. In addition to a complete survey of this field, a productive chapter concerns the psychotherapeutic possibilities. It discusses special indications and methods in a masterly manner. Two further chapters deal with the very important field 'The experts'

appraisement following sexual abuse'. The lengthy final chapter lays particular emphasis on the affirmative consideration of salutogenetic factors. Under certain circumstances, serious infantile traumatizations could be sufficiently mastered. Therefore 'this good outcome of a bad beginning' would be an equally relevant research topic in comparison with that of'the bad outcome'. On the basis of their data evaluation, the editors conclude that the risk of becoming a victim of abuse and emotional neglect is increased under the vari-

ables: female gender, social poverty, origin from a broken family and disability.

The borderline syndrome, a relevant and important theme in the field of psychiatry, psychotherapy and psychosomatics is dealt with in 'Borderline disorders theory and practice' by Dr. Birger Dulz (Senior Physician, General Psychiatric Hospital Ochsenzoll, Hamburg, Germany) and co-workers. This very remarkable book is a kind of optimal pocket book for doctors, nurses, social workers, educationalists, etc. who work with patients suffering from 
personality disorders on a therapeutic basis. The authors' comprehensive experience in diagnosis (including the traumatic genesis) on a descriptive and a structural level is evident. Their expertise is also displayed in their descriptions of countertransference, socio- and pharmacotherapy.

Additionally, an impressive chapter discusses the close cooperation of the doctors, nurses, social workers and educationalists activities in the sense of a therapeutically orientated system, which promotes the patients treatment. A further distinguishing feature of this chapter deals with the team members' individual and interpersonal difficulties. In his introduction Dr. Otto Kernberg appreciates the great scientific and applicable quality of Dr. Dulz' book.

The textbooks in the field of psychotherapy and psychosomatics have increased in Germany since the beginning of the nineties. At least 16 textbooks now exist. The rise in the amount of textbooks is not only due to competition between publishing houses but also to considerable increase in interested readers (doctors, psychologists, nurses, students). They are in urgent need of basic psychotherapeutic and psychosomatic knowledge to supplement their practical training. This stimulating development is based upon the following four tendencies in Germany: Firstly, the gathering of knowledge for the purpose of becoming a specialist in psychotherapeutical medicine; secondly, the additional training in psychotherapy fulfilling one of the basic requirements of a psychiatrist; thirdly, offering postgraduate psychologicomedical education for specialists in other medical fields (e.g. general practitioner, internist, gynecologist); fourthly, the presentation of some study material to supplement psychosomatic education with the object of realizing psychosomatic basic care. Colleagues who have a command of German and are interested in studying the theoretical basic knowledge of the above mentioned four tendencies will profit from Dr. Stephan Ahrens' book whose title in English is 'Psychotherapeutic medicine' (Dr. Ahrens is the Director. Department of Psychosomatics, General Hospital Rissen Hamburg, Germany).

Dr. Joachim Bauer's book (English title: The Alzheimer disease: neurobiology, psychosomatics, diagnostics and therapy) is an excellent scientific work. Dr. Bauer (Senior Physician, Department of Psychiatry, University of Freiburg, Germany) has a wide-ranging competence. This includes both biochemical applied knowledge recognition as a specialist in internal medicine and psychiatry including psychotherapy. Therefore, the author is able to present an interesting neurobiological theory. Founded upon experimental findings Dr. Bauer is also able to provide that psychosocial environmental influences play an important part in cortical plasticity in the age too.

KAR,GER. (C1997S. KargerAG, Basel

E-Mail karger@karger.ch Fax+416130612 34 http://www.karger.ch

That is to say: The promotion of the cortical plasticity by stimulating environmental influences is maintained in healthy persons but in the case of people of Alzheimer's disease inactivity, understimulation and persistent stress are observed. These influences include neurode-generative effects. Consequently, the author takes into consideration the possibility that psychosocial factors may play a part in Alzheimer dementia. After the careful examination of premorbid life careers of Alzheimer patients, Dr. Bauer found that the first cognitive symptoms of this disease could be connected with a long-standing preceding disactivation. These features are characterized by overprotection and ultimately motivation loss. The equally outstanding final chapter concerns 'The supportive measures' with providing relief techniques for the relatives too.

H. Freyberger, Hannover

Marc D. Feldman, Stuart J. Eisendraht (eds)

The Spectrum of Factitious Disorders 
American Psychiatric Press, Washington, 1996229 pp., 9 tab.; USD 36.-ISBN 0-88048-909-X Dr. Marc D. Feldman, Associate Professor, is Director of Psychiatry at the University of Alabama, Birmingham (UAB). Dr. Stuart J. Eisendraht is Professor of Clinical Psychiatry at the University of California, San Francisco School of Medicine.

The 'Spectrum of factitious disorders' is an excellent book for professionals. It offers a comprehensive overview of current thinking about patients who feign or induce illness - in themselves or others -to accrue the intangible benefits of the 'sick' role. This volume covers innovative psychotherapeutic techniques which stress the need to treat these patients with acceptance and understanding. First-person accounts illustrate the intense feelings mobilized in friends, family members, caregivers, and in patients themselves as factitious disorders play out. The book also presents a management approach emphasizing respect for the patient, no matter what the symptomatology.

Using abundant case material this work of the editors and nine notable co-contributors aids mental health practitioners to understand the phenomenon of 'disease forgery', and address its inherent management challenges. Furthermore, relevant information on ethical and legal issues concerning factitious disorders is given. Finally, clinical features, detection, and management of factitious disorders by proxy are explored, along with comprehensive psychosocial assessment and legal issues in such cases.

Regrettably, factitious disorders occurring with the medical (assistant) profession is treated too superficially.

I agree with the comment by Dr. Thomas N. Wise (Editor-in-chief, Psychosomatics) that 'this volume is solely dedicated to this topic and deserves to be in the library of all interested clinicians'.

H. Freyberger, Hannover

Ulrich Sachsse

Selbstverletzendes Verhalten

Vandenhoeck \& Ruprecht, Göttingen, 1996205 pp., DEM 42.-

ISBN3-525-45771-5

Dr. Ulrich Sachsse is senior physician at the General Hospital of Psychiatry, Göttingen (Germany). He is also research chief and head of a clinical department specializing in the treatment of patients suffering from self-mutilating acting out. Furthermore, Dr. Sachsse is a psychoanalyst and honorary professor at University of Kassel, Germany. The author's book entitled, 'Self-mutilating behavior' includes psychodynamic and psychotherapeutic aspects within a problematic patients' group. It also carefully deals with the highly relevant concepts of'trauma' and 'dissociation'.

Dr. Sachsse has extensive experience in the treatment of self-mutilating patients ranging from 18 to 28 years of age. The self-destructive modalities of predominantly female patients were characterized by the following: the cutting of the skin deep into the muscles tissue, burning of the skin by cigarettes or a flat iron, scalding over vast areas of the skin with hot water and cauterization from acids, and 'delicate self-cutting'. The author's well-established therapeutic concept begins with the emergency room admission. It is later continued with psychotherapeutic treatment in the closed ward and then in the open ward. Finally, long-term psychotherapy on an outpatient basis takes place. Following his introductory chapter entitled 'The beginning of the therapeutic relationship’ Dr. Sachsse deals with the diagnostic aspects. The author's trauma therapeutic procedures are based on the psychotherapeutic experiences which may be derived from both his imaginative work with traumatized persons based upon hypnotherapy and 
catathymic imaginative psychotherapy. In regard to countertransference, Sachsse describes his basic therapeutic attitude towards long-term psychotherapy sessions in an unusually differentiated manner. The following chapters are entitled 'The psychosynthetic furtherance of the good' and 'The deconstruc-tive dealing with the bad'. These two very informative chapters are then followed by two further chapters entitled 'Pathocure in the sense of a progression' and 'The step-by-step loosening from the therapeutic relationship'. According to the author, a relatively good prognosis may be expected in those patients who show the features 'intelligence', 'former traits of ego strenght' and 'degree of differentiated development concerning the cognitive and conscience structure'.

The scientific and practice-related importance of this book is established by Dr. Sachsse's impressing talent to represent in a very clear manner his understanding of symptom formation and concrete therapeutic strategy. Consequently, the reader is able to study the author's conclusions and to use the information to help in building up of ones' own individual therapeutic strategies. The great quality of Dr. Sachsse's 'Vademecum' has found expression in the fact that the existing third edition closely followed the first and the second editions in 1994 and 1995, respectively. The fourth edition is currently in preparation.

H. Freyberger, Hannover 